\title{
Optimization of metal inert gas-welded aluminium 6061 pipe parameters using analysis of variance and grey relational analysis
}

\author{
Ibrahim Sabry' ${ }^{1}$ Abdel-Hamid I. Mourad ${ }^{2,3}$ (D) Dinu Thomas Thekkuden ${ }^{2}$
}

Received: 7 November 2019 / Accepted: 3 January 2020 / Published online: 9 January 2020

(c) Springer Nature Switzerland AG 2020

\begin{abstract}
It is an underlying fact for the case of the joining process especially welding to have optimized parameters in order to achieve joints with outstanding mechanical characteristics. In the current work, aluminium 6061 pipes were welded using gas metal arc welding process with appropriate ER 4043 electrode and argon shielding gas. Optimum welding parameters (namely, current, voltage and travel speed) are investigated using analysis of variance ANOVA and grey relational analysis GRA statistical approaches. High tensile strength and low corrosion rate were set as required characteristics of quality welds. Since there are two responses and two objectives, multiple-criteria decision-making approach-GRA, and ANOVA are performed. Optimal parameters from these statistical approaches are converged to $110 \mathrm{~A}, 19 \mathrm{~V}$ and $3 \mathrm{~cm} /$ min, respectively. It is deduced from this study that the optimal parameters are convergent irrespective of the two used techniques for the investigated experimental data.
\end{abstract}

Keywords Metal inert gas welding · Aluminium 6061 - Parameter optimization · Analysis of variance · Grey relational analysis · Statistical analysis

\section{Introduction}

There is an increasing demand for materials having higher strength-to-weight ratio especially used for space applications. Therefore, aluminium alloys were the one of the most suitable substitutes for ferrous alloys due to their high strength and light weight characteristics. In 2017, aluminium production has increased by $5.8 \%$ worldwide. Al 6061 is a widely used alloy material for the production of aerospace, aircraft and gas turbine components. Al 6061 pipes have also been used for a broad range of applications, but they usually exhibit poor corrosion resistance properties.
In high strength aluminium pipe AA6061-T3, the second phase particles contribute to precipitation hardening but it can also induce susceptibility to localized corrosion [1-4]. In turn, the localized corrosion induced by microstructural heterogeneity leads to corrosion-assisted fatigue cracking or stress corrosion cracking $[5,6]$. Stress corrosion cracking usually results in premature failure. The combined effect of corrosive environment and stress accelerates the crack growth leading to reduced life of the components $[7,8]$. Localized corrosion causes deterioration in service to aluminium alloy components. This is one of the reasons for initiating fatigue cracking under alternating or constant tension [9-11]. The cracks developed

Abdel-Hamid I. Mourad: On leave from Mechanical Design Department, Faculty of Engineering, El Mataria, Helwan University, Cairo, Egypt.

$\triangle$ Abdel-Hamid I. Mourad, ahmourad@uaeu.ac.ae | ${ }^{1}$ Manufacturing Engineering Department, Modern Academy for Engineering and Technology, P.O. Box. 11571, Cairo, Egypt. ${ }^{2}$ Mechanical Engineering Department, College of Engineering, United Arab Emirates University, P.O. Box. 15551, Al-Ain, United Arab Emirates. ${ }^{3}$ Mechanical Design Department, Faculty of Engineering, El Mataria, Helwan University, Cairo, Egypt. 
as a result propagate under severe load, and the fracture toughness of the welded material gets adversely affected [12-18]. Unfortunately, various element additions for increased mechanical performance, easiness of processing and application stability create sites susceptible to localized corrosion [19]. Internal corrosion of aluminium pipelines is a common and serious problem in irrigation systems, which are designed for long-term operation. It involves an interaction between the flowing fluids and the metal wall. This problem has caused the consideration of many corrosion control programmes and research in various water fields around the world. Joining of pipelines in irrigation systems has usually threaded joints. On the other hand, if high pressure is present, welding techniques are rather used. Generally, it is difficult for aluminium alloys to be fusion welded and even it is not recommended at all for specific ranges of aluminium alloy groups. Also, the welding types have a crucial effect on the mechanical and metallurgical properties of the joints [20]. Novel techniques are suggested in such cases to join using the friction stir welding process [21-23]. Parameters play a crucial role in the case of friction stir welding [24]. Weld porosity and slag inclusion defects are formed due to the rapid oxidation during the fusion welding [25]. These defects have a great reduction effect of the mechanical properties of welded joints [26-28]. Commercial aluminium alloys have an additional demerit to be fusion welded. They have a protective hard adhered oxide film on the surface. That leads to an extensive surface treatment for the disposal of such film before welding. The diffused coatings laid over the surface to protect the tubes can be depleted during welding. In addition, welding introduces microstructural and compositional heterogeneities which can lead to significantly increased corrosion. In metal inert gas (MIG) welding, there is no uniform corrosion resistance of the welded joint at different zones and also joints are merely sensitive to corrosion. Furthermore, 78\% [29] of corrosion damage sites have been identified in the welded region and found to have initiated fatigue cracks. As a result, welding of aluminium and its alloys considering the final corrosion rate of the joint is challenging, especially if the joint is in a piping system for irrigation.

The mechanical properties of the final welded joint are affected by various parameters such as voltage, current, travel speed, wire feed rate and electrode thickness. Welding speed is a dominant variable in changing the welded joint's mechanical properties [30]. The effect of welding speed on the Al 6081 joint's fatigue strength was studied especially in the friction stir welding process. Also, the results obtained were compared with those acquired by MIG-pulse and tungsten inert gas (TIG) welding processes. However, lowering the value of welding speed significantly increased the fatigue strength of MIG-pulse and TIG-welded joints. Also, the joint welded by MIG-pulse process has the lowest value of fatigue strength compared to the friction stir welds (FSW) and TIG welds [31]. In MIG welding, the accurate filler metal selection is one of the most substantial factors to consider. Its deposit chemistry with the shielding gas determines the final mechanical properties of the weld. Si-rich filler metal-ER-4043 and MG-rich filler metal-ER-5356 are the most widely used filler metals for welding Al 6061 joints. Rajesh Verma [32] studied the effect of ER4043 and ER5356 filler wire on mechanical properties and microstructure of dissimilar aluminium alloys, 5083-O and 6061-T6 joints, welded by the inert metal gas welding process. The hot crack which is one of the defects developed during MIG welding mainly depends on filler composition and mitigation. Sirich filler metals such as ER-4043 were found to be more effective to reduce hot cracks in Al 6061 welds [32]. It is more efficient than using Mg-rich filler metals such as ER5356 where longitudinal cracks were observed in the latter [33]. Also, ER-4043 is useful in minimizing the brittle intermetallic compound layer and preventing its build-up [34]. ER-4047 filler can be used as an alternative of ER-4043 as it showed a competitive output quality for welding $\mathrm{Al}$ 6061 [34]. However, it is unusual to be familiar with the possessions of alternative filler metals like ER4047 on the Al 6061 welds.

Subsequently, to solve multiple objective problems, several techniques are available such as grey relational analysis (GRA) and Technique for Order priority through resemblance to Ideal Solution (TOPSIS) [35]. GRA is based on grey system theory, suitable for solving problems with the complex relationship between several factors and variables. GRA can be utilized for solving various types of multi-attribute decision-making problems such as power allocation, quality amelioration and resource exploitation in the industry [36]. GRA solves the multi-attribute problem by collecting all the attribute values into a single value; thus, the multi-objective problem is transformed into a single objective problem [37]. Subsequently, the GRA decreases complexity in decision-making and increases the adequacy of the system [38]. Hsuan-Liang Lin [39] optimized the process parameters of MIG welding utilizing GRA style. In that work, the depth to width ratio of weld bead at two various stipulations has been optimized by converting the problem into a single objective. Hsiao et al. [17] solved the multi-objective problem in plasma arc welding (PAW) to get better the quality of weld utilizing GRA. The grey relational grade was computed for responses such as root penetration, groove width and undercut and later used for optimizing the parameters using the Taguchi approach. However, statistical approaches used for optimizing the MIG welding parameters for welding Al 6061 pipes are rare. Welding of 
Table 1 Chemical composition (weight \%) of Al 6061

\begin{tabular}{lllllllll}
\hline Element & $\mathrm{Si}$ & $\mathrm{Fe}$ & $\mathrm{Cu}$ & $\mathrm{Min}$ & $\mathrm{Mg}$ & $\mathrm{Cr}$ & $\mathrm{Zn}$ & $\mathrm{Ti}$ \\
\hline Weight \% & 0.4 & 0.70 & 0.15 & 0.15 & 0.9 & 0.04 & 0.25 & 0.15 \\
\hline
\end{tabular}

Table 2 Mechanical properties of Al 6061

\begin{tabular}{llll}
\hline Alloy & $\begin{array}{l}\text { Tensile strength } \\
(\mathrm{MPa})\end{array}$ & $\begin{array}{l}\text { Elongation per- } \\
\text { centage }(\%)\end{array}$ & $\begin{array}{l}\text { Vickers hardness } \\
(\mathrm{HV})\end{array}$ \\
\hline 6061 & 252.690 & 8 & 86 \\
\hline
\end{tabular}

pipes is preferred rather than flanges for those applications in which high pressure is exerted on the inner surface of the pipes.

This research investigates the influence of welding parameters on the tensile strength and corrosion rate of gas metal arc-welded (GMAW) Al 6061 pipe. The study is expected to provide information regarding the optimized parameters and statistical approaches. Literature on gas metal arc-welded Al 6061 pipes and optimization of parameters for multi-objective responses (Tensile strength and corrosion rate) are limited. The primary objective is to successfully weld the Al 6061 pipes using the MIG process and thereafter to investigate the effect of welding parameters on the tensile strength and corrosion rate. Comparison of two statistical approaches-ANOVA and GRA - are analysed.

\section{Methods and materials}

Al 6061 pipes with a $30 \mathrm{~mm}$ outer diameter and $3 \mathrm{~mm}$ wall thickness were the coupons for gas metal arc welding. The chemical composition and mechanical properties of Al 6061 aluminium according to the datasheet provided by Miser Aluminum Company are given in Tables 1 and 2, respectively. The welding setup includes Trans Pulse Synergic 4000 power source, ER-4043 electrode wire and Al 6061 coupons. The chemical composition of the ER-4043 electrode is provided in Table 3.

This research focusses on the effect of three important GMAW welding parameters namely welding current, voltage and travel speed on the tensile strength and corrosion rate. Therefore, three factors with three levels are considered for the statistical analysis using ANOVA and GRA. The upper and lower limits of the three factors are
Table 4 MIG process parameters and their limits in metal inert gas

\begin{tabular}{lllrrr}
\hline Process Parameters & Units & Symbol & \multicolumn{3}{l}{ Limits } \\
\cline { 3 - 6 } & & & \multicolumn{1}{l}{0} & \multicolumn{1}{l}{1} \\
\hline Current & Ampere (A) & $\mathrm{I}$ & 105 & 110 & 115 \\
Voltage & Volt (V) & $\mathrm{U}$ & 17 & 18 & 19 \\
Travel speed & $\mathrm{cm} / \mathrm{min}$ & $\mathrm{S}$ & 3 & 4 & 5
\end{tabular}

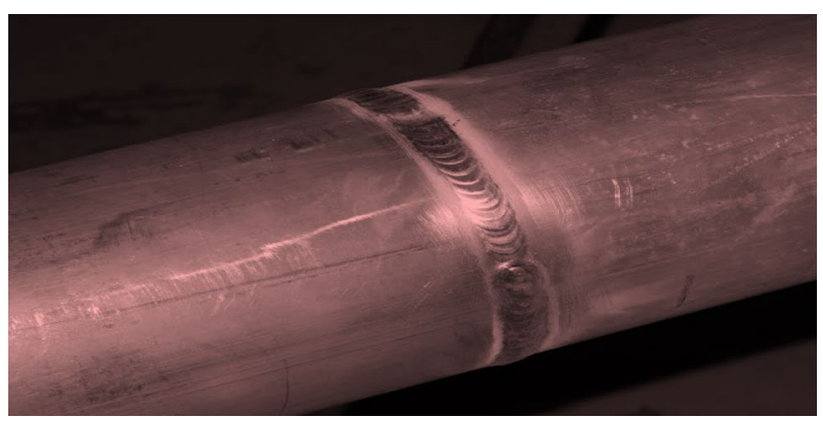

Fig. 1 A sample of MIG-welded pipe

obtained from the preliminary trials and previous studies. The parameter range was set in such a way that the final welded joint has no defects upon visual inspection. The GMAW process parameters and their limits are presented in Table 4. A welded AA 6061 pipe using the MIG process is demonstrated in Fig. 1.

\subsection{Electrochemical testing}

Cell current readings were taken during a short, slow sweep of the potential. The sweep was taken from $(-100$ to 100) $\mathrm{mV}$ relative to open circuit potential (OCP). The scan rate defines the speed of the possible sweep in $\mathrm{mV} / \mathrm{sec}$ and (10) mv. The tests were carried out using a multi-channel WENKING Mlab potentiostat and a corrosion measuring system SCl-Mlab (from Bank Electronics-Intelligent Control $\mathrm{GmbH}$, Germany 2007). A saturated calomel electrode was submerged in the salt solution as a working electrode (WE) and aluminium 6061 samples were the counter electrodes. Tafel's electrochemical corrosion test was performed using
Table 3 Chemical composition (wt\%) of electrode-ER 4043

\begin{tabular}{llllllll}
\hline Element & $\mathrm{Si}$ & $\mathrm{Mg}$ & $\mathrm{Cu}$ & $\mathrm{Fe}$ & $\mathrm{Mn}$ & $\mathrm{Zn}$ & $\mathrm{Ti}$ \\
\hline Weight \% & 5.0 & 0.005 & 0.3 & 0.8 & 0.05 & 0.1 & 0.2 \\
\hline
\end{tabular}


samples in $3.5 \%$ sodium chloride solution, $\mathrm{NaCl}$ with $\mathrm{Ph}$ of 6.8 and tap water with $\mathrm{Ph}$ of 8.2. The corrosion parameters such as corrosion potential (Ecorr) and corrosion current (Icorr) at each shot was determined. For each specimen, the corrosion rate was examined and the current corrosion weight was obtained by extrapolation.

\subsection{Tensile testing}

Tensile test specimens were prepared as per ASTM E8 standard (See Fig. 2). Three samples were tested for each set of parameters (See Table 4), and the average values of the results were obtained.

\section{Procedure for grey relational analysis}

In GRA, all the response values are normalized between 0 and 1 for simple interpretation and analysis. These normalized values are utilized to calculate the grey relational (GR) coefficient. Following, the grey relational grade for every experimental trial is calculated by averaging the GR coefficient. The ranking based on the responses of the experimental trial depends on GR grade (GRG). The higher GR grade corresponds to the optimal set of parameters and will be ranked as 1 . The ranking based on GRG is explained step by step.

Step 1 All the response values are normalized based on the required condition by utilizing the equations given below. Normalization for larger the better is calculated using Eq. (1).

$x_{i}(k)=\frac{y_{i}(k)-\min _{i}(k)}{\operatorname{maxy}_{i}(k)-\operatorname{miny}_{i}(k)}$

Normalization for smaller the better is calculated using Eq. (2)

$x_{i}(k)=\frac{\operatorname{maxy}_{i}(k)-y_{i}(k)}{\operatorname{maxy}_{i}(k)-\operatorname{miny}_{i}(k)}$

where $x_{i}(k$ (is the normalized value of output response, $\min$ $y_{i}\left(k\right.$ (is the least value of $y_{i}\left(k\right.$ (for $k$ th response, $\max y_{i}(k$ (is highest value of $\left.y_{i}\right) k$ (for $k$ th response.

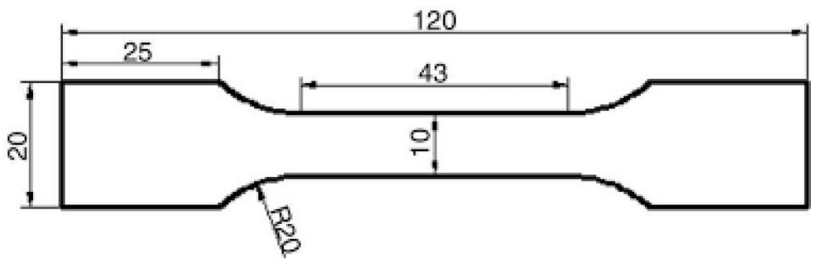

Fig. 2 Dimensions of tensile test sample (dimensions are in $\mathrm{mm}$ )
Step 2 GR coefficient is calculated to establish a correlation between exemplary and actual normalized value. It is expressed as in Eq. (3)

$\zeta_{i}(k)=\frac{\Delta_{\min }+\psi \Delta_{\max }}{\Delta_{o i}(k)+\psi \Delta_{\max }}$

$\Delta_{o i}(k)=\left|x_{0}(k)-x_{i}(k)\right|, \psi$ is distinctive coefficient, which is used to expand or compress the range of grey relational coefficient. The value of distinctive coefficient normally lies within 0 and 1 . But no matter what the value of $\psi$ is, the rank of $\zeta_{i}(\mathrm{~K})$ will always be the same. $\psi$ value of 0.5 is preferable $[17,18] . \Delta_{\min }$ is minimum value of $\Delta_{\mathrm{oi}}$ and $\Delta_{\max }$ is maximum value of $\Delta_{\mathrm{o}}$.

Step 3 The grey relational grade (GRG) can be calculated using Eq. (4)

$\gamma_{i}=\frac{1}{n} \sum_{i=1}^{n} \zeta_{i}(k)$

where $\gamma_{i}$ is grey relational grade and $\mathrm{n}$ is number of the output responses.

\section{Results and discussion}

\subsection{Analysis of variance (ANOVA)}

The full factorial analysis was conducted by performing the design of experiments. Current, voltage and travel speed were the selected parameters, and tensile strength and corrosion rate were the responses investigated. The main effect plots of parameters to the tensile test and corrosion rate are shown in Figs. 3 and 5. There was a significant change in the magnitude of tensile strength for each of the parameter from a level to another. Table 5 provides information about the significance of main effects and interaction effects based on the probability value ( $p$ value) for the response-tensile strength. It is evident from the result that all three individual parameters are significant as their $p$ values are less than 0.05 for a 95\% confidence interval. $F$ value is another statistic in ANOVA used to determine whether the test is statistically significant or not. The $F$ values of voltage, current and travel speed were $65.81 \mathrm{~V}, 8.32 \mathrm{~A}$ and $5.81 \mathrm{~cm} / \mathrm{min}$, respectively. Higher the $F$ value, more is the significance of the parameter to the response. Hence, voltage is more significant to the tensile strength compared to current and travel speed. $F$ value is also inversely proportional to the $p$ value. From the interaction plot shown in Fig. 4, and Table 5, the interaction of the current and voltage to the travel speed was not significant ( $p$ value $>0.05$ ) while the interaction between the current and the voltage was significant ( $p$ value $<0.05$ ) 
Fig. 3 Main effect plots for tensile strength (tensile strength is in $\mathrm{MPa}$ )
Main Effects Plot for Tensile strength Fitted Means

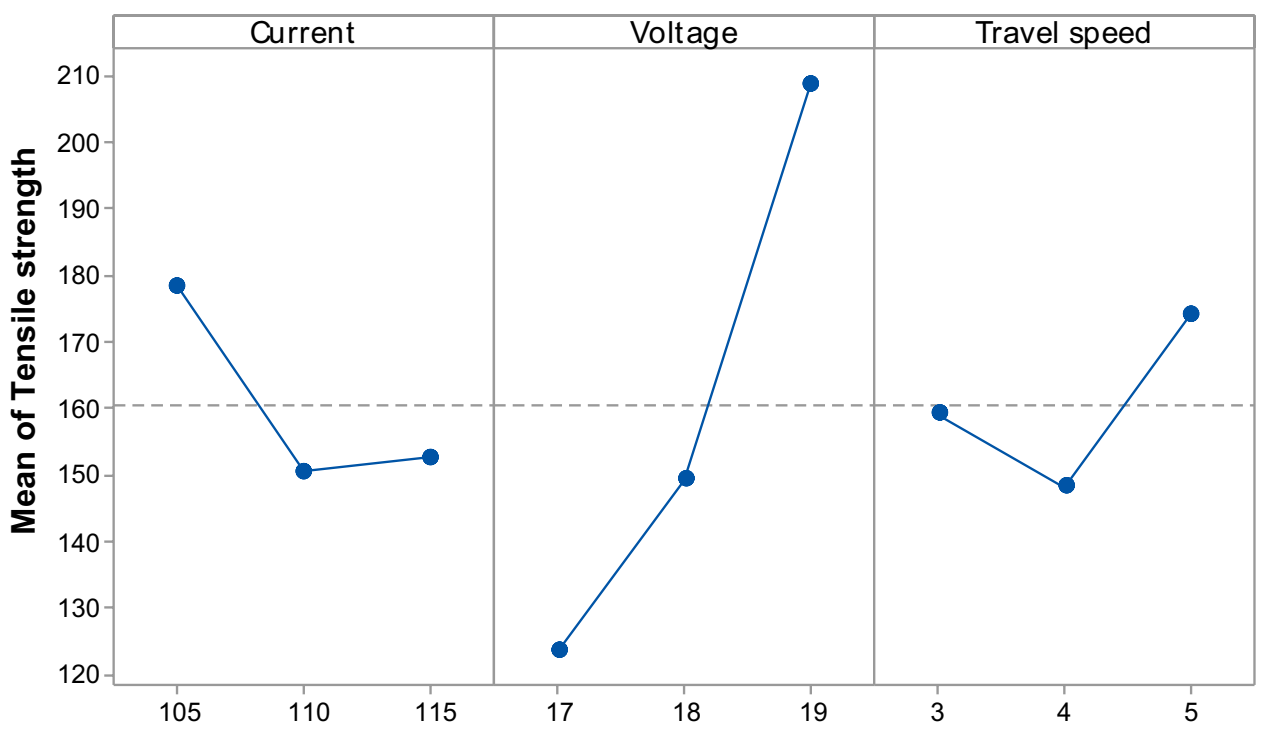

Table 5 Statistics of main effect and interaction effect on tensile strength

\begin{tabular}{lrrrrrrr}
\hline Source & DF & Seq SS & Contribution (\%) & Adj SS & Adj MS & FValue & $P$ Value \\
\hline Model & 18 & 55152.2 & 96.33 & 55152.2 & 3064.0 & 11.67 & 0.001 \\
Linear & 6 & 41967.8 & 73.30 & 41967.8 & 6994.6 & 26.65 & 0.000 \\
$\quad$ Current & 2 & 4366.4 & 7.63 & 4366.4 & 2183.2 & 8.32 & 0.011 \\
$\quad$ Voltage & 2 & 34551.3 & 60.35 & 34551.3 & 17275.7 & 65.81 & 0.000 \\
$\quad$ Travel speed & 2 & 3050.0 & 5.33 & 3050.0 & 1525.0 & 5.81 & 0.028 \\
2-way interactions & 12 & 13184.4 & 23.03 & 13184.4 & 1098.7 & 4.19 & 0.025 \\
$\quad$ Current* Voltage & 4 & 9483.0 & 16.56 & 9483.0 & 2370.7 & 9.03 & 0.005 \\
$\quad$ Current* Travel speed & 4 & 3405.3 & 5.95 & 3405.3 & 851.3 & 3.24 & 0.074 \\
$\quad$ Voltage* Travel speed & 4 & 296.1 & 0.52 & 296.1 & 74.0 & 0.28 & 0.882 \\
Error & 8 & 2099.9 & 3.67 & 2099.9 & 262.5 & & \\
Total & 26 & 57252.1 & 100.00 & & & & \\
\hline
\end{tabular}

Table 6 shows the ANOVA result for the corrosion rate. From the statistical analysis considering three parameters and three levels, it is evident that all the main effects of the parameters and their interaction effects are not significant to the corrosion rate as their $p$ values are greater than 0.05 in $95 \%$ confidence interval. The reason behind the insignificance is due to the negligible change in the corrosion rate for each parameter from one level to another (See Fig. 5). Similar findings were observed from the interaction plots (see Fig. 6) where the interactions were found to be insignificant due to a small change in the corrosion rate. The $p$ values for all the interactions such as current-voltage, current-travel speed, voltage-travel speed were more than 0.05 in a $95 \%$ confidence interval. Also, $F$ values were low proving the insignificance of the interaction effect of parameters to the corrosion rate. This evidently proved that the corrosion rate is not dependent on the welding process parameters. However, both the tensile strength and corrosion rate are investigated in this study to optimize the parameters. Figure 7 shows the optimized parameters (welding current, welding voltage and travel speed) and the corresponding response values (tensile strength and corrosion rate) from the response optimizer in ANOVA. Response optimizer can determine the right combination of parameters for a single response or for set of responses. In this case, an optimization plot was generated after optimizing multiple responses for the three input variables. The optimized welding current, welding voltage and travel speed were $110 \mathrm{~A}, 19 \mathrm{~V}$ and $3 \mathrm{~cm} / \mathrm{min}$, respectively.

\subsection{Grey relational analysis (GRA)}

Grey relational analysis is one of the statistical approaches used here to optimize the welding process parameters. The 
Fig. 4 Interaction effect plots for tensile strength (tensile strength is in $\mathrm{MPa}$ )

\section{Interaction Plot for Tensile strength}

Fitted Means

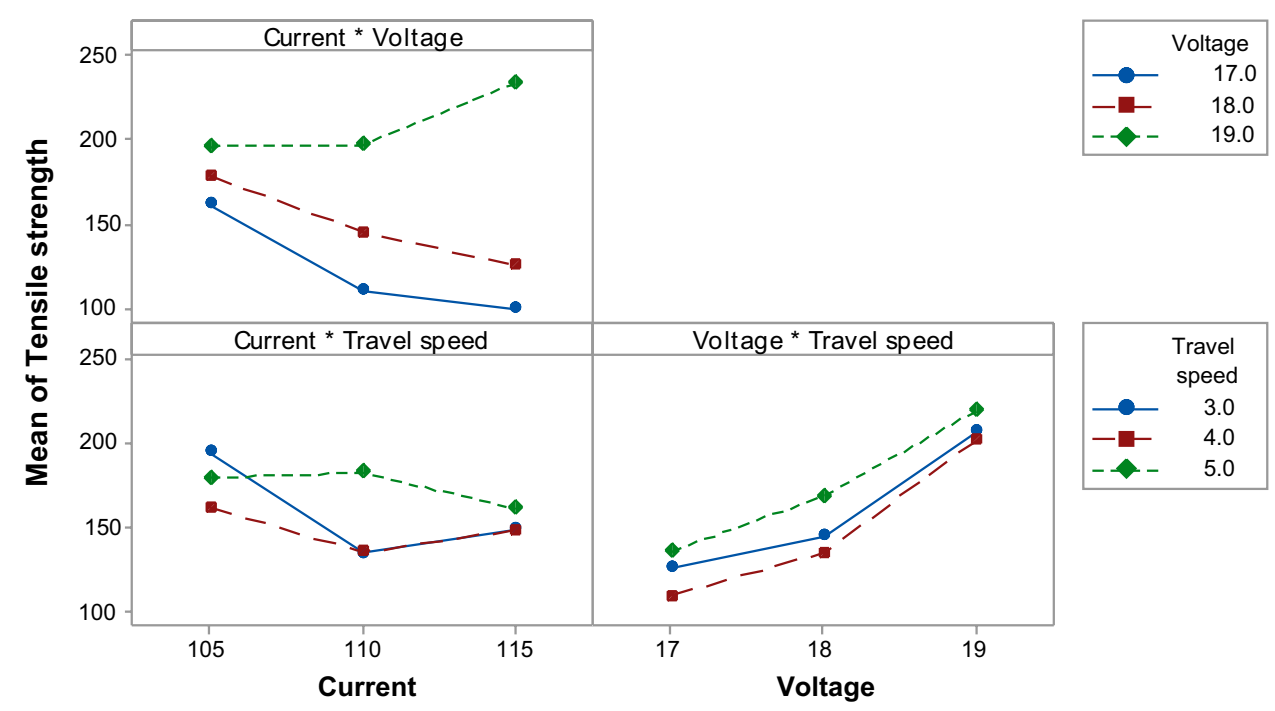

Table 6 Main effect and interaction effect on corrosion

\begin{tabular}{lrlccccc}
\hline Source & DF & Seq SS & Contribution (\%) & Adj SS & Adj MS & FValue & $P$ Value \\
\hline Model & 18 & 0.001424 & 51.96 & 0.001424 & 0.000079 & 0.48 & 0.906 \\
$\quad$ Linear & 6 & 0.000465 & 16.96 & 0.000465 & 0.000077 & 0.47 & 0.813 \\
$\quad$ Current & 2 & 0.000352 & 12.85 & 0.000352 & 0.000176 & 1.07 & 0.387 \\
$\quad$ Voltage & 2 & 0.000031 & 1.14 & 0.000031 & 0.000016 & 0.09 & 0.911 \\
$\quad$ Travel speed & 2 & 0.000081 & 2.97 & 0.000081 & 0.000041 & 0.25 & 0.787 \\
2-way interactions & 12 & 0.000959 & 35.00 & 0.000959 & 0.000080 & 0.49 & 0.875 \\
$\quad$ Current *Voltage & 4 & 0.000404 & 14.74 & 0.000404 & 0.000101 & 0.61 & 0.665 \\
$\quad$ Current *Travel speed & 4 & 0.000383 & 14.00 & 0.000383 & 0.000096 & 0.58 & 0.684 \\
$\quad$ Voltage *Travel speed & 4 & 0.000172 & 6.27 & 0.000172 & 0.000043 & 0.26 & 0.895 \\
Error & 8 & 0.001316 & 48.04 & 0.001316 & 0.000165 & & \\
Total & 26 & 0.002740 & 100.00 & & & & \\
\hline
\end{tabular}

same approach is used for the grey relational analysis as of ANOVA where current, voltage and travel speed were the parameters, and tensile strength and corrosion rate were the responses. Since the tensile strength has to be maximized while the corrosion rate has to be minimized, GRA is suitable for multi-objective criterion analysis. The output responses were normalized using equation considering the higher the better for tensile strength and the lower the better for corrosion rate. Table 7 presents the normalized value of the experimental result, grey coefficient and grey relational grade calculated using Eqs. (1)-(4). The distinctive coefficient was taken as 0.5 . Normalization, division square and grey coefficient were calculated for each of the parameters, that is for tensile strength and corrosion rate. The grey relational grade was calculated by taking the average of grey coefficient obtained for tensile strength and corrosion rate. The ranking was allotted based on the GRG. In this case, the highest GRG was found to be
0.802004 and hence assigned as rank 1. According to GRA, optimal parameters correspond to rank 1. In this case, optimal parameters such as voltage, current and travel speed were $19 \mathrm{~V}, 110 \mathrm{~A}$ and $3 \mathrm{~cm} / \mathrm{min}$, respectively. For these parameters, the tensile strength was 200.3 MPa and the corrosion rate was 0.004 MPY. Among the experimental trials, 200.3 MPa was close to the highest tensile strength (253.86 MPa) and 0.004 MPY was the least corrosion rate. Least rank of 27 was obtained for the least GRG (0.398631). The parameters were $110 \mathrm{~A}, 17 \mathrm{~V}$ and $4 \mathrm{~cm} / \mathrm{min}$, and the tensile strength and corrosion rate were 100.3 $\mathrm{MPa}$ and 0.026 MPY. Therefore, the tensile strength for the rank 27 was close to the least $(90.62 \mathrm{MPa})$ and the corrosion rate was close to the highest (0.04 MPY). It is worth to mention that the optimal parameters obtained by ANOVA and GRA are same (110 A, $19 \mathrm{~V}$ and $3 \mathrm{~cm} / \mathrm{min})$.

Mean closeness coefficient of GRG at each level of the single parameter with a combination of rest two parameters 
Fig. 5 Main effect plots for corrosion rate (corrosion rate is in MPY)
Main Effects Plot for Corrosion rate

Fitted Means

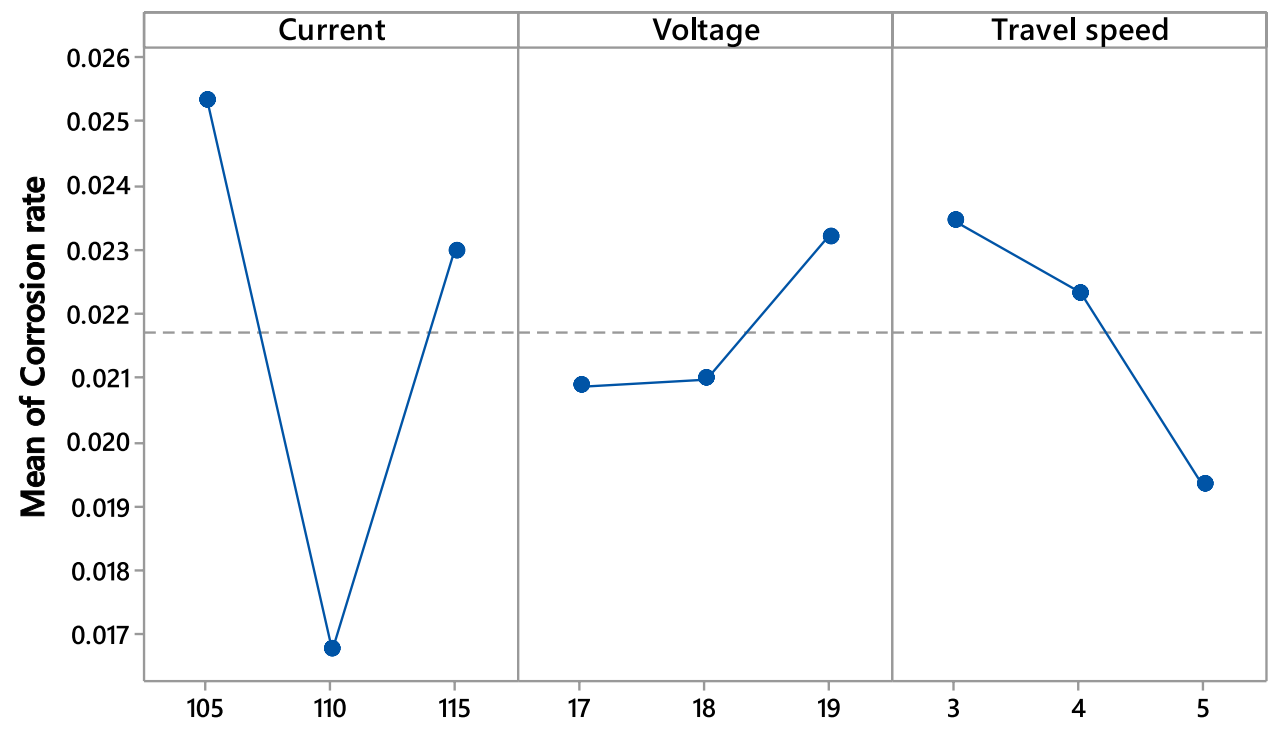

Fig. 6 Interaction effect plots for corrosion rate (corrosion rate is in MPY)

\section{Interaction Plot for Corrosion rate Fitted Means}

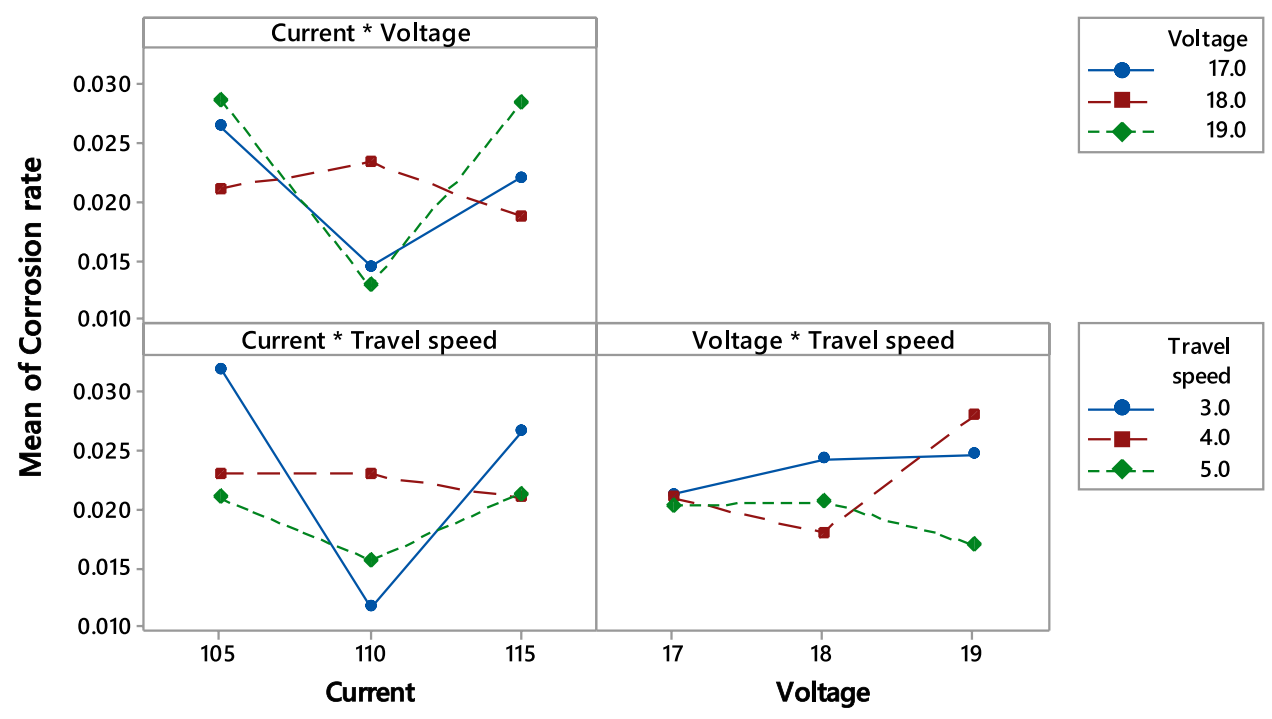

is shown in Table 8 and Fig. 8. The highest GRG for each of the parameters-current, voltage and travel speed-was obtained for respective levels $(110 \mathrm{~A}, 18 \mathrm{~V}$ or $19 \mathrm{~V}$ and $5 \mathrm{~cm} /$ $\mathrm{min})$. The optimal parameters have only a slight change in the travel speed. Therefore, it is concluded that the interaction of parameters has an influence on GRG rather than the main effect of each of the parameters.

\section{Conclusion}

Metal inert gas welding process was effectively used for joining aluminium pipes. The process parameters were found to be significant factors affecting tensile strength. Therefore, optimization of parameters is important to 
Fig. 7 Optimized parameters and responses using response optimizer in ANOVA

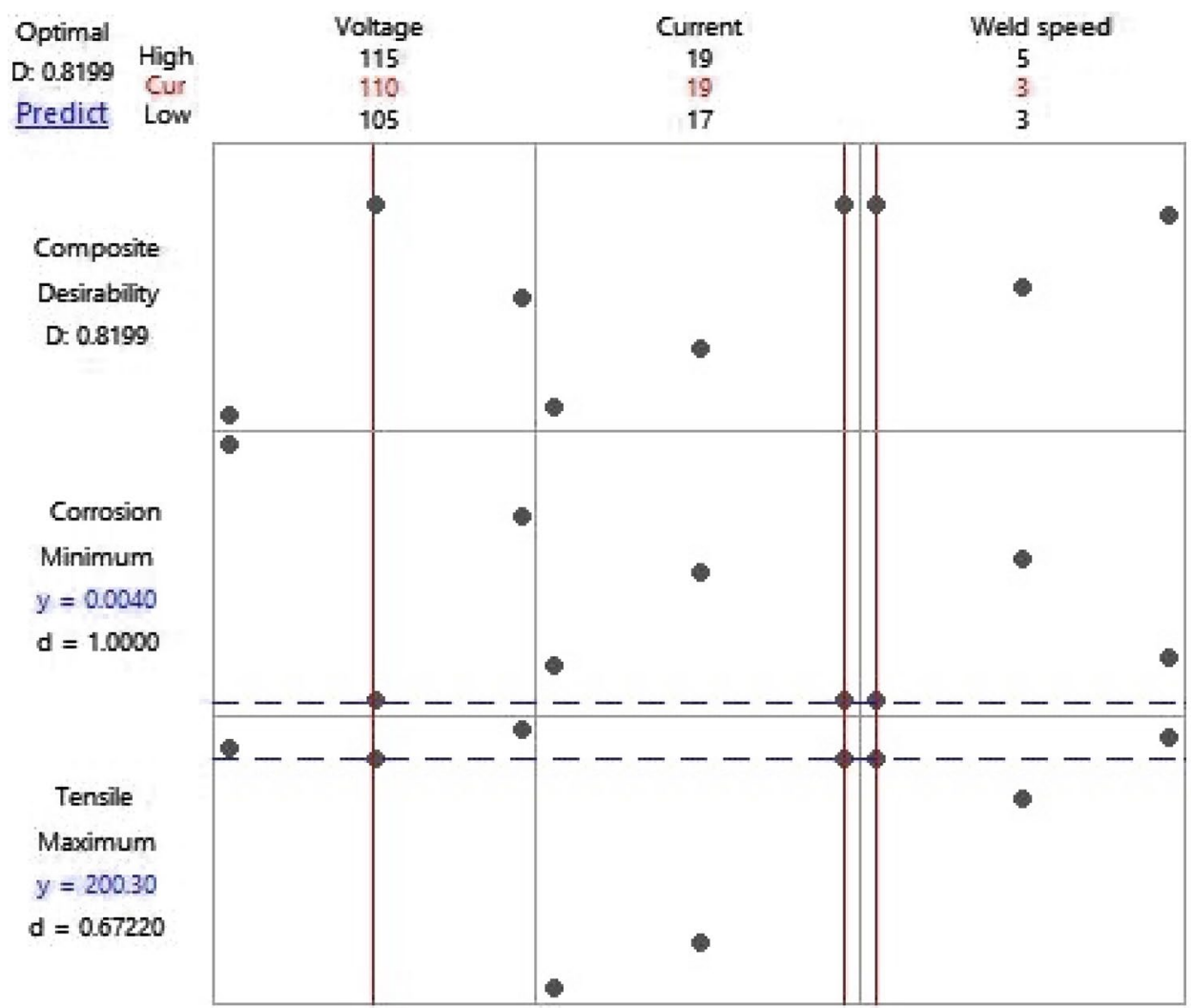

achieve strengthened joint. The analysis results by conducting ANOVA and GRA are provided below.

- The $p$ values of current, voltage, travel speed and current-voltage interaction from ANOVA are less than 0.05 in $95 \%$ confidence interval. Therefore, it is confirmed that the current, voltage, travel speed and the interaction between current and voltage have a significant effect on the tensile strength.

- The $p$ values of current, voltage, travel speed, currentvoltage interaction, current-travel speed interaction, voltage-travel speed interaction are $0.387,0.911,0.787$, $0.665,0.684$ and 0.895 , respectively. All the $p$ values are greater than 0.05 in a $95 \%$ confidence interval. Therefore, neither the main effect of the parameters nor their interactions are significant to the corrosion rate.

- A systematic approach was conducted in order to perform a grey relational analysis. Ranking of the experi- mental runs was allotted according to grey relational grade. Rank 1 was allotted to the highest GRG for which the parameters are $110 \mathrm{~A}, 19 \mathrm{~V}$ and $3 \mathrm{~cm} / \mathrm{min}$. Since higher tensile strength and lower corrosion rate are the required objective characteristics, set of parameters corresponding to rank 1 is optimum.

- The optimized parameters obtained from GRA and ANOVA are $110 \mathrm{~A}, 19 \mathrm{~V}$ and $3 \mathrm{~cm} / \mathrm{min}$. The results from both of these analyses converged to a single optimal set of parameters irrespective of the statistical analysis investigated.

- Multi-criteria decision-making approach using GRA and ANOVA are effective for optimizing the parameters. Both statistical approaches can be easily operated by welders from initial welding trials to select right parameters. 


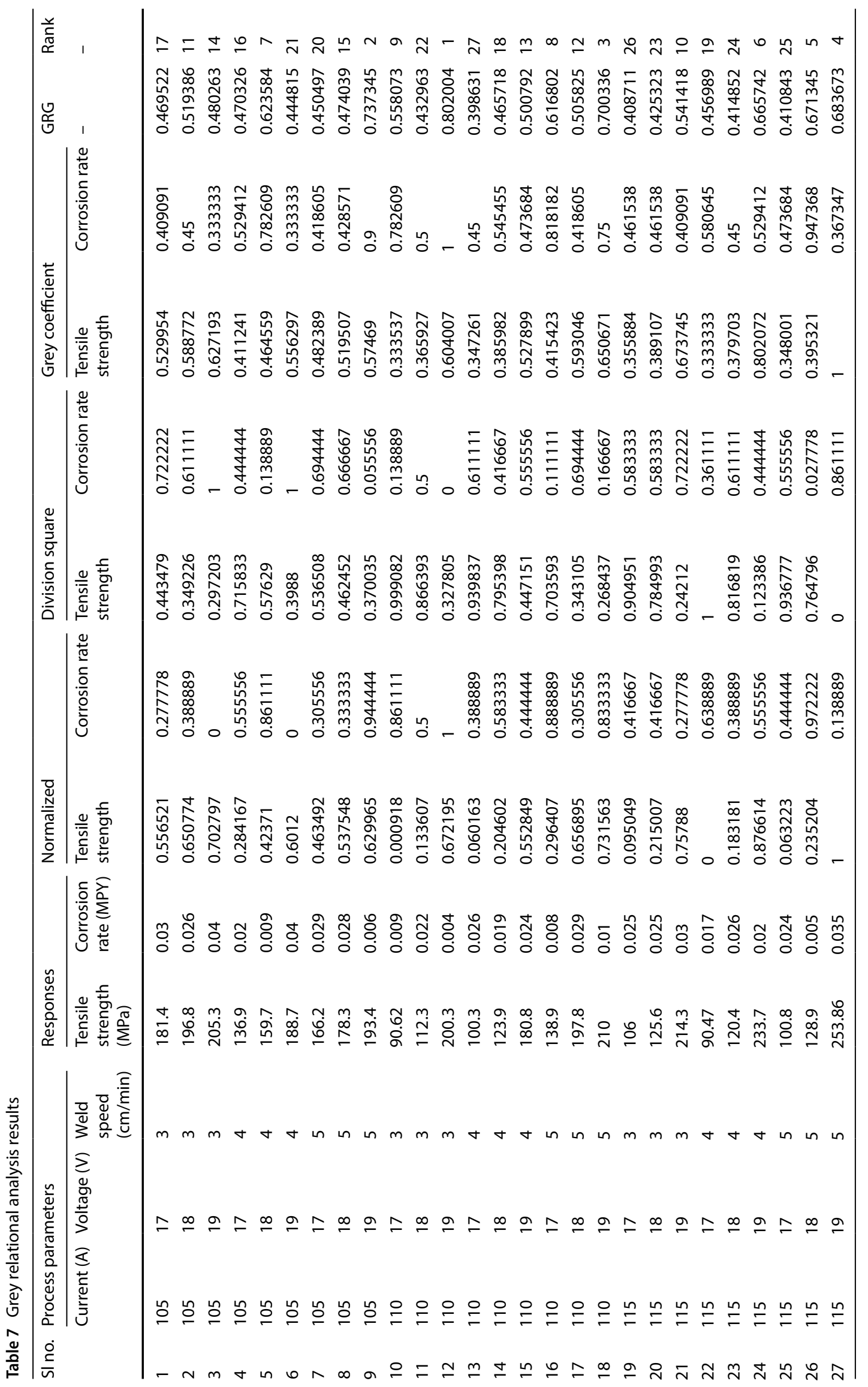


Table 8 Mean closeness coefficient of each parameter at every level

\begin{tabular}{llll}
\hline Parameters & \multicolumn{3}{l}{ Average grey relation grade } \\
\cline { 2 - 4 } & Level 1 & Level 2 & Level 3 \\
\hline Ampere (I) & 0.518864 & 0.55346 & 0.519877 \\
Voltage (V) & 0.471155 & 0.50367 & 0.50367 \\
Travel speed (S) & 0.515296 & 0.493494 & 0.583412 \\
\hline
\end{tabular}

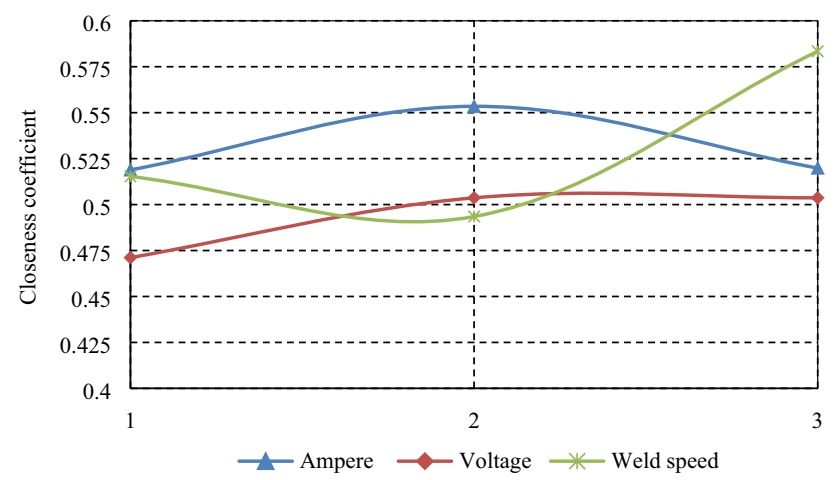

Fig. 8 Effect of process parameter on closeness coefficient

Acknowledgements We would like to acknowledge the fund provided by the United Arab Emirates University through the grant number 31R105-Research center.

\section{Compliance with ethical standards}

Conflict of interest On behalf of all authors, the corresponding author states that there is no conflict of interest.

\section{References}

1. Zhou C, Yang X, Luan G (2006) Effect of root flaws on the fatigue property of friction stir welds in 2024-T3 aluminum alloys. Mater Sci Eng A 418:155-160

2. Lienert TJ, Stellwag WL Jr, Grimmett BB, Warke RW (2003) Friction stir welding studies on mild steel. Weld J New York 82:1-S

3. Merchant SY (2015) Investigation on effect of welding current on welding speed \& hardness of HAZ \& weld metal of mild steel. Int J Res Eng Technol 4:44-48

4. Hamilton C, Dymek S, Blicharski M (2007) Mechanical properties of al 6101-T6 welds by friction stir welding and metal inert gas welding. Arch Metall Mater 52:67

5. Rahman ABMM, Kumar S, Gerson AR (2010) The role of silicon in the corrosion of AA6061 aluminium alloy laser weldments. Corros Sci 52:1969-1975

6. Mathers G (2002) The welding of aluminium and its alloys. Woodhead Publishing, Cambridge

7. Alzafin YA, Mourad AHI, Zour MA, Abuzeid OA (2009) Stress corrosion cracking of $\mathrm{Ni}$-resist ductile iron used in manufacturing brine circulating pumps of desalination plants. Eng Fail Anal 16:733-739. https://doi.org/10.1016/j.engfailana I.2008.06.013

8. Aljoboury Al, Mourad AHI, Alawar A et al (2010) Stress corrosion cracking of stainless steels recommended for building brine recirculation pumps. Eng Fail Anal 17:1337-1344. https ://doi.org/10.1016/j.engfailanal.2010.03.008

9. Squillace A, De Fenzo A, Giorleo G, Bellucci F (2004) A comparison between FSW and TIG welding techniques: modifications of microstructure and pitting corrosion resistance in AA 2024T3 butt joints. J Mater Process Technol 152:97-105

10. Song JL, Lin SB, Yang CL, Fan CL (2009) Effects of Si additions on intermetallic compound layer of aluminum-steel TIG welding-brazing joint. J Alloy Compd 488:217-222

11. Rao KP, Ramanaiah N, Viswanathan N (2008) Partially melted zone cracking in AA6061 welds. Mater Des 29:179-186

12. Maiti SK, Kishore GK, Mourad A-H (2008) Bilinear CTOD/CTOA scheme for characterisation of large range mode I and mixed mode stable crack growth through AISI 4340 steel. Nucl Eng Des 238:3175-3185

13. Maiti SK, Mourad A-H (1995) Criterion for mixed mode stable crack growth-II. Compact tension geometry with and without stiffener. Eng Fract Mech 52:349-378

14. Maiti SK, Namdeo S, Mourad AHI (2008) A scheme for finite element analysis of mode I and mixed mode stable crack growth and a case study with AISI 4340 steel. Nucl Eng Des 238:787-800

15. Mourad AHI, Alghafri MJ, Zeid OAA, Maiti SK (2005) Experimental investigation on ductile stable crack growth emanating from wire-cut notch in AISI 4340 steel. Nucl Eng Des 235:637-647

16. Mourad A-HI, El-Domiaty A, Chao YJ (2013) Fracture toughness prediction of low alloy steel as a function of specimen notch root radius and size constraints. Eng Fract Mech 103:79-93

17. Mourad A-H, Maiti SK (1995) Influence of state of stress on mixed mode stable crack growth through D16AT aluminium alloy. Int J Fract 72:241-258

18. Mourad A, Maiti SK (1996) Mode II stable crack growth. Fatigue Fract Eng Mater Struct 19:75-84

19. Dhancholia DD, Sharma A, Vyas C (2014) Optimisation of friction stir welding parameters for AA 6061 and AA 7039 aluminium alloys by response surface methodology (RSM). Int J Adv Mech Eng 4:565-571

20. Mourad AHI, Khourshid A, Sharef T (2012) Gas tungsten arc and laser beam welding processes effects on duplex stainless steel 2205 properties. Mater Sci Eng A 549:105-113. https://doi. org/10.1016/j.msea.2012.04.012

21. Sabry I, El-Kassas AM, Mourad A-HI et al (2019) Friction stir welding of T-Joints: experimental and statistical analysis. J Manuf Mater Process 3:38

22. Mourad AHI, Allam M, El Domiaty A (2014) Study on the mechanical behavior of aluminum alloy 5083 friction stir welded joint. In: ASME 2014 pressure vessels and piping conference. American Society of Mechanical Engineers, pp V06AT06A014-V06AT06A014

23. Mourad A-HI, Harib KH, El-Domiaty A (2010) Fracture behavior of friction stir spot welded joint. In: ASME 2010 pressure vessels and piping division/K-PVP conference. American Society of Mechanical Engineers, pp 205-215

24. El-Kassas AM, Sabry I, Mourad A-HI, Thekkuden DT (2019) Characteristics of potential sources-vertical force, torque and current on penetration depth for quality assessment in friction stir welding of AA 6061 pipes. Int Rev Aerosp Eng (IREASE) 12(4):2019

25. Thekkuden DT, Mourad A-HI (2019) Investigation of feed-forward back propagation ANN using voltage signals for the early prediction of the welding defect. SN Appl Sci 1:1615 
26. Thekkuden DT, Santhakumari A, Sumesh A, Mourad A-HI, Rameshkumar K (2018) Instant detection of porosity in gas metal arc welding by using probability density distribution and control chart. Int J Adv Manuf Technol 95(9-12):4583-4606

27. Thekkuden DT, Mourad A-HI, Christy JV, Idrisi AH (2018) Assessment of weld quality using control chart and frequency domain analysis. In: ASME 2018 pressure vessels and piping conference. American Society of Mechanical Engineers, pp V06BT06A004-V06BT06A004

28. Sumesh A, Thekkuden DT, Nair BB et al (2015) Acoustic signature based weld quality monitoring for SMAW process using data mining algorithms. Applied Mechanics and Materials. Trans Tech Publications, Pfaffikon, pp 1104-1113

29. Ghali E (2010) Corrosion resistance of aluminum and magnesium alloys: understanding, performance, and testing. Wiley, New York

30. Abbasi K, Alam S, Khan MI (2012) An experimental study on the effect of MIG welding parameters on the weld-bead shape characteristics. Int J Eng Sci Technol 2(4):599-602

31. Jannet S, Mathews PK, Raja R (2013) Comparative investigation of friction stir welding and fusion welding of 6061-T6 and 5083-O aluminum alloy based on mechanical properties and microstructure. J Achiev Mater Manuf Eng 61:181-186

32. Verma RP, Pandey KN, Sharma Y (2015) Effect of ER4043 and ER5356 filler wire on mechanical properties and microstructure of dissimilar aluminium alloys, 5083-O and 6061-T6 joint, welded by the metal inert gas welding. Proc Inst Mech Eng Part B J Eng Manuf 229:1021-1028

33. Azida N, Lah C, Ibrahim MFA et al (2011) The effect of filler ER4043 and ER5356 on porosity distribution of welded AA6061 aluminum alloy. Advanced Materials Research. Trans Tech Publications, Pfaffikon, pp 987-990

34. Shah LH, Azhani N, Razak A, Juliawati A, Ishak M (2013) Investigation on the mechanical properties of TIG welded AA6061 alloy weldments using different aluminium fillers. GSTF J Eng Technol 2(2):116-120

35. Adalarasan R, Santhanakumar M, Sundaram AS (2014) Optimization of weld characteristics of friction welded AA 6061-AA 6351 joints using grey-principal component analysis (G-PCA). J Mech Sci Technol 28:301-307

36. Kuo Y, Yang T, Huang G-W (2008) The use of grey relational analysis in solving multiple attribute decision-making problems. Comput Ind Eng 55:80-93

37. Kuo Y, Yang T, Huang G-W (2008) The use of a grey-based Taguchi method for optimizing multi-response simulation problems. Eng Optim 40:517-528

38. Liu H-T, Cheng H-S (2016) An improved grey quality function deployment approach using the grey TRIZ technique. Comput Ind Eng 92:57-71

39. Lin H-L (2012) The use of the Taguchi method with grey relational analysis and a neural network to optimize a novel GMA welding process. J Intell Manuf 23:1671-1680

Publisher's Note Springer Nature remains neutral with regard to jurisdictional claims in published maps and institutional affiliations. 